\title{
LOW EMITTANCE LATTICES FOR THE DUKE FEL STORAGE RING*
}

\author{
S.F.Mikhailov, V.N.Litvinenko, FEL Laboratory, Duke University, Durham, NC, USA \\ Y.Wu, ALS, LBNL, Berkley, CA, USA
}

\section{Abstract}

In this paper we present two options for a new lattice of the $1 \mathrm{GeV}$ Duke FEL Storage Ring reducing horizontal beam emittance from existing $18 \mathrm{~nm} * \mathrm{rad}$ to $1.4 \mathrm{~nm} * \mathrm{rad}$ and $0.9 \mathrm{~nm} * \mathrm{rad}$ respectively. One of proposed lattices reuses existing magnetic elements, another is based on completely new design. The use of combined function magnets with dipole, quadrupole and sextupole components allows us to keep the ring compact and fit it into existing footprint. 2D and 3D field simulations for such a magnet showed good quality of magnetic field. Preliminary results for dynamic aperture simulations are also presented. We also discuss the choice of lattice cell and tune advances and the concept of local compensation of nonlinear aberrations.

\section{INTRODUCTION}

The $1 \mathrm{GeV}$ Duke storage ring is designed to accommodate a variety of FELs [1,2]. Its 34-meter long, dispersion-free straight sections and their flexible lattices provide the perfect environment for installation of various FEL systems and optimisation of lattices for their best performance $[3,4]$. The fundamental principle providing simultaneously for this flexibility and for large dynamic aperture is the local compensation of the non-linear geometrical aberrations (LCNGA), developed and tested at Duke FEL laboratory [5]. The main source of nonlinear aberrations are sextupoles in the arcs, which are required for the chromaticity compensation and control. LCNGA concept limits all significant geometrical aberrations to exist only within the arcs. Therefore, the choice of the linear lattice in the straight section does not significantly affect the dynamic aperture of the ring. This feature proved to be very important for accommodating both the 7.5-m long OK-4 with plane wigglers and $28-\mathrm{m}$ long OK-5 FEL with helical wigglers $[3,4]$ without any changes in the arc lattice.

Even though the performance of the Duke storage ring and its lattice is rather remarkable [6], its natural horizontal emittance $\varepsilon_{x}=18 \mathrm{~nm}$ rad at $1 \mathrm{GeV}$ is too large for very short wavelength FELs with wavelength at and below $100 \mathrm{~nm}$. The existing arcs lattice was constrained by hardware, to be exact the vacuum chambers, which were designed and built in Stanford in mid-eighties. The hardware was brought to Duke University and imposed the FODO lattice for the ring's arcs. The use of old vacuum chambers also defined rather large longitudinal impedance of the system. The alternative lattice with $\varepsilon_{x}=3$ $\mathrm{nm}$ * rad emittance was dismissed as too expensive.

\footnotetext{
*This work is supported by the Dean of Natural Sciences, Duke University
}

Table 1: General parameters

\begin{tabular}{|c|c|c|c|}
\hline & Now & \multicolumn{2}{|c|}{ Upgrades } \\
\hline Maximum Energy [GeV] & \multicolumn{3}{|c|}{1.2} \\
\hline Nominal Energy $[\mathrm{GeV}]$ & \multicolumn{3}{|c|}{1.0} \\
\hline Injection energy [GeV] & 0.25 & 0.25 & -1.2 \\
\hline Circumference [m] & \multicolumn{3}{|c|}{107.46} \\
\hline RF frequency [MHz] & \multicolumn{3}{|c|}{178.547} \\
\hline Number of bunches & \multicolumn{3}{|c|}{$1-64$} \\
\hline $\begin{array}{l}\text { Horizontal emittance } \varepsilon_{x} \\
\text { at } E=1 \mathrm{GeV}[\mathrm{nm} \times \mathrm{rad}]\end{array}$ & 18 & 1.4 & 0.87 \\
\hline $\begin{array}{l}\text { Radiation losses per } \\
\text { revolution }[\mathrm{KeV}]\end{array}$ & 42.0 & 34.6 & 29.2 \\
\hline Damping times at $1 \mathrm{GeV}$ & & & \\
\hline Horizontal $\tau_{x}[\mathrm{~ms}]$ & 18.3 & 12.2 & 13.9 \\
\hline Vertical $\tau_{y}[\mathrm{~ms}]$ & 17.0 & 20.7 & 24.6 \\
\hline Longitudinal $\tau_{E}[\mathrm{~ms}]$ & 8.2 & 16.0 & 20.0 \\
\hline Momentum compaction & 0.0086 & 0.0022 & 0.0017 \\
\hline $\begin{array}{l}\text { Natural chromaticities: } \\
\text { Horizontal } d Q_{x} / d \delta \\
\text { Vertical } d Q_{v} d d \delta\end{array}$ & $\begin{array}{l}-10.0 \\
-9.8\end{array}$ & $\begin{array}{l}-26.1 \\
-11.5\end{array}$ & $\begin{array}{l}-34.7 \\
-12.8\end{array}$ \\
\hline $\begin{array}{l}\text { Betatron tunes: } \\
\text { Horizontal } Q_{x} \\
\text { Vertical } Q_{y} \\
\text { Longitudinal } Q_{s} \\
\text { at } U_{R F}=850 \mathrm{kV} \\
\end{array}$ & $\begin{array}{c}9.11 \\
4.18 \\
0.0086\end{array}$ & $\begin{array}{l}12.11 \\
6.13 \\
.0044\end{array}$ & $\begin{array}{c}14.12 \\
6.146 \\
0.0038\end{array}$ \\
\hline $\begin{array}{l}\text { Longitudinal emittance } \\
\mathcal{E}_{S}[\mu \mathrm{m}]\end{array}$ & 5.75 & 3.84 & 3.00 \\
\hline
\end{tabular}

Thus, the Duke storage ring did not reach emittance of the third generation light sources and should be classified as the "second-and-half" generation.

At present, the OK-4/Duke storage ring FEL reached a wavelength range where emittance could be the main limiting factor [7]. The installation of the advanced OK-5 FEL on the Duke storage ring makes it natural to advance other ring's parameters such as the emittance and the longitudinal impedance. These improvements would provide for the OK-5 FEL gain measured in hundreds of percents and for its effective operation in the VUV [8]. In this paper we focus on the two versions of the new lattice providing for low emittance.

\section{LINEAR AND NON-LINEAR ASPECTS OF THE NEW LATTICES}

We constrained both of the new lattices to fit the layout of the existing Duke storage ring. The first lattice with $\varepsilon_{x}=1.4 \mathrm{~nm} * \mathrm{rad}$ is a "cost effective" solution based on the re-use of existing magnetic elements. The upgrade of the ring for this lattice would require: 
Table 2: Magnetic system and lattice parameters.

\begin{tabular}{|c|c|c|c|}
\hline & \multirow[t]{2}{*}{ Now } & \multicolumn{2}{|c|}{ Upgrades } \\
\hline & & $1.4 \mathrm{~nm}$ & $0.9 \mathrm{~nm}$ \\
\hline Number of cells & 20 & 24 & 28 \\
\hline Number of dipoles & 40 & 48 & 30 \\
\hline Number of arc quads & 42 & 48 & 28 \\
\hline \multicolumn{4}{|c|}{ Parameters of the dipoles at $E=1 \mathrm{GeV}$ : } \\
\hline Dipole gap at $x=0[\mathrm{~cm}]$ & 2.4 & 2.5 & 2.4 \\
\hline Magnetic length [m] & 0.33 & 0.335 & 0.68 \\
\hline Dipole field $B_{0}[\mathrm{kGs}]$ & 15.7 & 13.05 & 11.01 \\
\hline Gradient $G[\mathrm{kGs} / \mathrm{cm}]$ & 0 & -1.175 & -1.416 \\
\hline $\mathcal{B}_{v}{ }^{\prime \prime} d s[\mathrm{kGs} / \mathrm{cm}]$ & -2.25 & -15.8 & -24.0 \\
\hline $\begin{array}{l}\text { Parameters of the quads } \\
\text { at } E=1 \mathrm{GeV} \text { : }\end{array}$ & $\begin{array}{l}\text { QF } \\
\text { QD }\end{array}$ & $\begin{array}{l}\text { QF1 } \\
\text { QF2 } \\
\end{array}$ & $\overline{\mathrm{QF}}$ \\
\hline Bore diameter [cm] & \multicolumn{2}{|c|}{4.0} & 3.0 \\
\hline Magnetic length [m] & $\begin{array}{l}0.20 \\
0.14\end{array}$ & $\begin{array}{l}0.20 \\
0.14\end{array}$ & 0.36 \\
\hline Gradient $G[\mathrm{kGs} / \mathrm{cm}]$ & $\begin{array}{c}3.18 \\
-2.73 \\
\end{array}$ & 3.28 & 3.81 \\
\hline $\begin{array}{l}\text { Sextupole } B^{\prime \prime} \\
{\left[\mathrm{kGs} / \mathrm{cm}^{2}\right]}\end{array}$ & $\begin{array}{r}0.266 \\
-0.228 \\
\end{array}$ & 0.372 & 0.573 \\
\hline $\begin{array}{l}\text { Beta functions and } \\
\text { dispersion in arcs: }\end{array}$ & \multicolumn{3}{|c|}{$\begin{array}{l}\min \\
\max \end{array}$} \\
\hline$-\beta_{x}[\mathrm{~m}]$ & $\begin{array}{l}0.43 \\
2.48 \\
\end{array}$ & $\begin{array}{l}0.15 \\
4.28 \\
\end{array}$ & $\begin{array}{l}0.10 \\
4.26 \\
\end{array}$ \\
\hline$-\beta_{y}[\mathrm{~m}]$ & $\begin{array}{l}1.56 \\
5.06\end{array}$ & $\begin{array}{l}0.77 \\
3.34\end{array}$ & $\begin{array}{l}0.73 \\
2.84\end{array}$ \\
\hline - $D_{x}[\mathrm{~cm}]$ & $\begin{array}{l}12.7 \\
24.5 \\
\end{array}$ & $\begin{array}{c}3.0 \\
11.3 \\
\end{array}$ & $\begin{array}{l}2.3 \\
8.2 \\
\end{array}$ \\
\hline \multicolumn{4}{|l|}{ Tune advances per cell: } \\
\hline$-\Delta Q_{x}$ & $3 / 10$ & $5 / 12$ & $3 / 7$ \\
\hline$-\Delta Q_{y}$ & $1 / 10$ & $1 / 6$ & $1 / 7$ \\
\hline
\end{tabular}

- Modification of the yokes in the existing dipoles;

- Reshuffling of the existing magnetic elements in the arcs;

- Modification of the supports to install two additional cells.

Second lattice with $\varepsilon_{x}=0.9 \mathrm{~nm} * \mathrm{rad}$ assumes completely new magnet design for the dipoles and quads (see Table 2). Tables 1 and 2 list the main parameters and compare the existing and the new lattices. Figures 1, 2 and 3 show $\beta$-functions and dispersion for the existing and the new lattices. The new lattices incorporate the new South straight section with the OK-5 FEL [4]. $\beta$-functions in the OK-5 straight section may independently varied within the range of $\beta_{x, y}=4-10 \mathrm{~m}$. The change of the tune/phase advance in the OK5 FEL straight section may be compensated in the RF/injection straight section.

The new lattices would reduce the horizontal beam emittance from $18 \mathrm{~nm} *$ rad to $1.4 \mathrm{~nm} * \mathrm{rad}$ and 0.87 $\mathrm{nm} * \mathrm{rad}$ accordingly. This is achieved with the use of combined function dipole magnets with strong quadrupole and sextupole components. It makes the regular cell more compact and provides for more cells per arc. The combination of the bending and vertical focusing

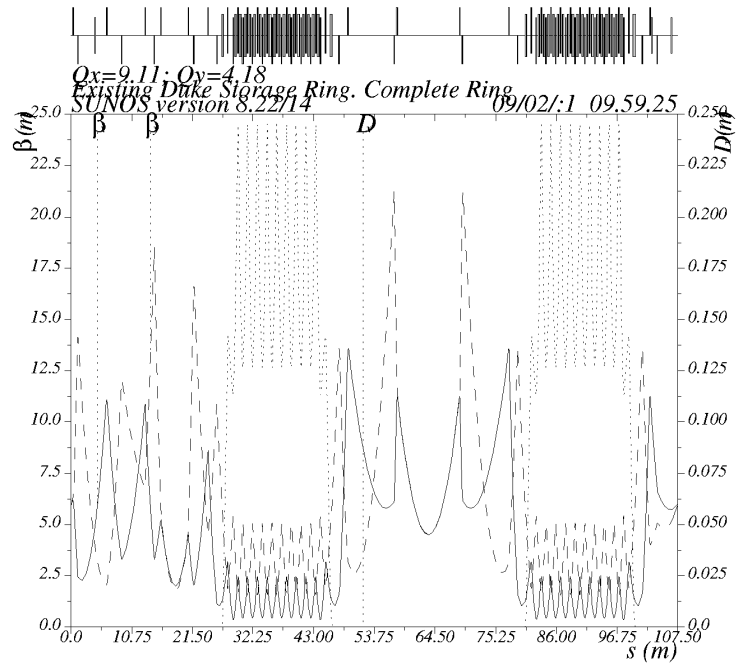

Figure 1: The existing lattice of the Duke storage ring. Solid line $-\beta_{x}$, dash line $-\beta_{y}$, dotted line $-D_{x}$.

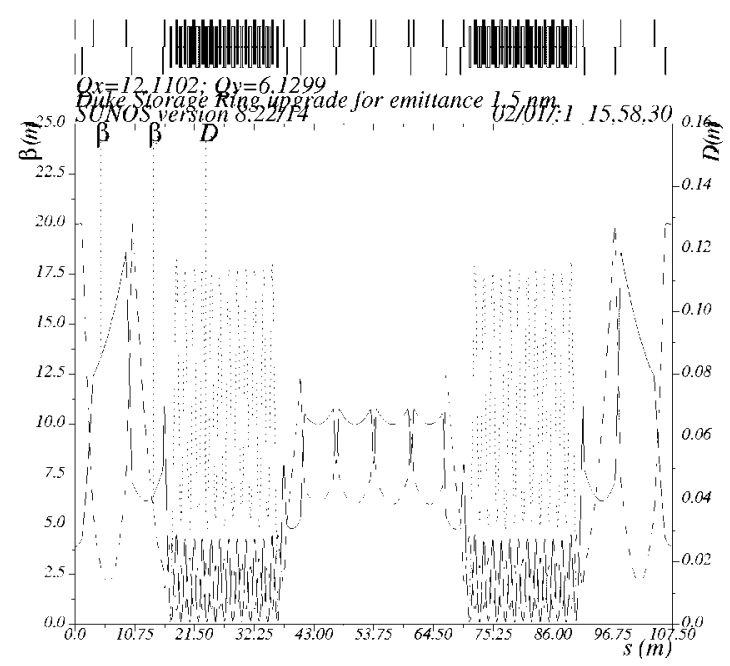

Figure 2: Upgrade lattice for $\varepsilon_{x}=1.4 \mathrm{~nm} * \mathrm{rad}$. Solid line - $\beta_{x}$, dash line $-\beta_{y}$, dotted line - $D_{x}$.

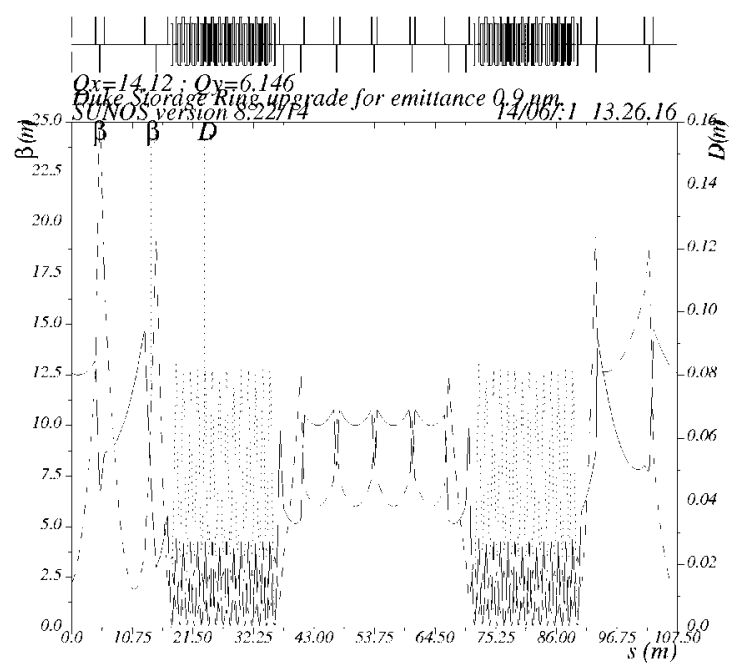

Figure 3: Upgrade lattice for $\varepsilon_{x}=0.9 \mathrm{~nm} * \mathrm{rad}$

Solid line $-\beta_{x}$, dash line $-\beta_{y}$, dotted line $-D_{x}$. 
functions in one element enables us to reduce the horizontal dispersion, and therefore, the emittance. Strong sextupole components in the dipoles and quadrupoles are necessary to compensate the vertical and horizontal chromaticity of the ring. The horizontal sextupole moment in the focusing quadrupoles is generated by asymmetric excitation of the coils. This method has been proved to be very efficient without serious side-effects. Stronger focusing in the arcs increases the absolute value of horizontal and vertical chromaticities in the upgrade lattices (see Table 1). In combination with substantially reduced values of dispersion, they require much stronger sextupoles in arc's dipoles and quadrupoles (see Table 2).

We used the MERMAID 2D/3D code [9] for magnetic design of the modified dipole. The lower value of the dipole filed (see Table 2) enables us to obtain good quality of magnetic field in the aperture of $\Delta x= \pm 2 \mathrm{~cm}$ for both versions of the dipole. The challenging part of the design was the attainment of the high quality sextupole field. The MERMAID 2D/3D code proved to be very efficient and reliable and allows us to avoid prototyping of the magnets.

The upgrade lattices have new configuration in the North straight section optimised for future installation of the modified OK-4 FEL and for the full energy injection from the future $1.2 \mathrm{GeV}$ booster [10]. Similar to the existing lattice, the new arc lattices have dispersionmatching end-cells providing for dispersion-free straight sections.

Both of the new lattices are based on the concept of local compensation of the second order geometrical aberrations (SOGA) [5] which is a modification of wellknown second order achromat [11]. This concept is used in the existing lattice and proved to be very effective. Strong, chromatic sextupoles in the arcs are the main nonlinear elements of the Duke storage ring. The choice of the tune advance per cell allows us to cancel the SOGA in the straight sections and make the dynamic aperture less susceptible to the specific lattice of the straight sections. In the next order, the sextupoles cause non-linear tune shifts. At large amplitudes of betatron oscillations, the non-linear tune shift causes a phase shift between the cells which violates exact compensation of the SOGA. This effect is most profound for the horizontal oscillations. We used one family of octupoles in the first version of upgrade lattice ( $\left.\varepsilon_{x}=1.4 \mathrm{~nm} * \mathrm{rad}\right)$ and two families in the second one $\left(\varepsilon_{x}=0.9 \mathrm{~nm} * \mathrm{rad}\right)$ to compensate non-linear tune shifts and, therefore, increase the dynamic aperture of the ring.

For simulation of dynamic aperture of the bare lattice we used the MAD8.22 code. After correction of the nonlinear tune shift, the horizontal dynamic aperture reached $55 \mathrm{~mm}^{*} \mathrm{mrad}$ for the lattice with $\varepsilon_{x}=1.4 \mathrm{~nm} * \mathrm{rad}$ and 28 $\mathrm{mm} * \mathrm{mrad}$ for that with $\varepsilon_{x}=0.9 \mathrm{~nm} * \mathrm{rad}$. The vertical dynamic aperture also increased up to $20 \mathrm{~nm} * \mathrm{rad}$ and 10 $n{ }^{*}$ rad. respectively. The energy deviation of $\pm 2 \%$ did not affect the dynamic aperture considerably. These preliminary results are very encouraging.
With the proposed modifications, the Duke FEL storage ring will join the family of the medium energy, third generation light sources, such as ELETTRA, ALS, SLS and BESSY-II.

\section{ACKNOWLEDGEMENTS}

The authors would like to thank Prof. Berndt Müller, the dean of natural Sciences, Duke University, for the support of this project. The authors are grateful to Dr. Andrey Dubrovin, Budker Institute of Nuclear Physics, Novosibirsk, Russia for providing the up-dated version of the Mermaid code.

\section{REFERENCES}

1] V.N. Litvinenko, S.H.Park, I.V.Pinayev, Y.Wu, M.Emamian, N.Hower, O.Oakeley, G.Swift, P.Wang, Nucl. Instr. and Meth A429 (1999) 151.

[2] V.N.Litvinenko, S.F.Mikhailov, N.A.Vinokurov, N.G.Gavrilov, D.A.Kairan, G.N.Kulipanov, O.A.Shevchenko, T.V.Shaftan, P.D.Vobly, Y.Wu, "The OK-5/Duke Storage Ring VUV FEL with Variable Polarization", accepted for publication in Proc. of $22^{\text {nd }}$ International FEL Conference, Durham, NC, August 13-18, 2000.

[3] Y.Wu, V.N.Litvinenko, E.Forest, J.M.J.Madey, Nucl. Instr. and Meth. A331 (1993) 287-292.

[4] Y.Wu, V.N.Litvinenko, S.F.Mikhailov, O.A.Shevchenko, N.A.Vinokurov, N.G.Gavrilov, T.V.Shaftan. D.A.Kairan, "Lattice Modifications and Nonlinear Dynamics for Elliptically Polarized VUV OK-5 FEL Source at Duke Storage Ring" for OK-5 FEL", accepted for publication in Proc. of $22^{\text {nd }}$ International FEL Conference, Durham, NC, August 13-18, 2000.

[5] V.N.Litvinenko, Y.Wu, B.Burnham, J.M.J. Madey, S.H.Park, Proc. of 1995 Particle Accelerator Conference, Dallas, TX, May 1-5, 1995, p.796.

[6] Y.Wu, V.N.Litvinenko, B.Burnham, S.H.Park and J.M.J.Madey, IEEE Transaction on Nuclear Science, Vol. 44, No. 5, October 1997, p.1753.

[7] V.N.Litvinenko, S.H.Park, I.V.Pinayev, Y.Wu, "Operation of the OK-4/Duke storage ring FEL below $200 \mathrm{~nm}$ ", accepted for publication in Proc. of $22^{\text {nd }}$ International FEL Conference, Durham, NC, August 13-18, 2000.

[8] V.N.Litvinenko, O.A.Shevchenko, N.A.Vinokurov, Y.Wu, "Predictions and Expected Performance for the VUV OK-5/Duke Storage Ring FEL with Variable Polarization", accepted for publication in Proc. of $22^{\text {nd }}$ International FEL Conference, Durham, NC, August 13-18, 2000.

[9] Mermaid, the 2D/3D code for magnetic design, (C) A.N.Dubrovin, Novosibirsk, Russia

[10] HI $\gamma \mathrm{S}$ proposal to the US Department of Energy, Technical Description, September 2000.

[11] K.L.Brown, "A second-order Magnetic Optical Achromat", SLAC report 2257. SLAC, February 1979 